\title{
ОБЪЕКТИВНОСТЬ ИСТОРИЧЕСКОГО ЗНАНИЯ И КРИТИЧЕСКИЙ РАЦИОНАЛИЗМ (К ВОПРОСУ О ВОЗМОЖНОСТИ ИСТОРИИ В СМЫСЛЕ НАУКИ)
}

\section{О.П. Панафидина}

Объективность знания по праву считается одним из главных признаков его научности. В то же время проблематичность достижения объективного гуманитарного знания зачастую служит одним из аргументов в пользу провозглашения этой сферы знания таковой, что выходит за рамки науки. Конечно, понятие гуманитарного знания не тождественно понятию научного знания, но означает ли это, что первое противостоит последнему? В решении данной проблемы в философии сложилось два противоположных подхода: (1) объективизм, претендующий на представление действительности как она существует сама по себе, безотносительно к познающему субъекту; (2) релятивизм (как «зеркальное отражение» объективизма), полагающий, что совпадение субъекта и объекта в гуманитарном познании якобы делает невозможным достижение объективного знания. Представители обоих подходов исходят из представления о научной объективности в смысле объектности, т.е. соотнесенности с объектом познания за счет устранения самого субъекта.

Преодоление дихотомии «объективизм-релятивизм», как нам представляется, возможно на пути альтернативного понимания научной объективности. Реальной альтернативой и классическому пониманию науки, и постмодернизму как современной разновидности релятивизма может быть постпозитивистское видение научного знания, которое в целом соответствует духу «коперниканского пере- 
ворота», осуществленного в гносеологии И. Кантом ${ }^{1}$. В связи с этим целью данной статьи является обоснование возможности достижения исторической объективности как условия возможности исторической науки в целом, исходя из концепции научной объективности в смысле интерсубъективности и истинности, разработанной К.Р. Поппером. Хотя ни Кант, ни Поппер специально не занимались проблемами исторической эпистемологии, с нашей точки зрения, их эпистемологические идеи вполне применимы к исторической науке.

Главное нововведение Канта, полностью принятое Поппером, состоит в его различении «вещей самих по себе»и «вещей как предметов опыта» (или же ноуменов в негативном смысле и феноменов). По сути, Кант четко разграничил сферы онтологии и гносеологии (точнее эпистемологии). Кроме того, Кант разработал теорию научного познания на основе синтеза эмпиризма и рационализма, чем обосновал необходимость теоретической науки, но в рамках возможного опыта. И наконец, своим учением об априорных формах познания Кант основывает учение о концептуальных схемах (или каркасах), что повлияло на оформление идеи о «теоретической нагруженности фактов». Что касается экспликации научной объективности, то Поппер утверждает, что его «способ использования терминов "объективный" и "субъективный” весьма напоминает кантовский» ${ }^{2}$.

Сравнивая эпистемологическое наследие Канта и Поппера, напрашивается еще одна аналогия. Влияние этих выдающихся философов на дальнейшее развитие философской мысли, бесспорно, огромное. Однако их многочисленные последователи, претендуя на разработку идей своих великих предшественников, на самом деле во многом пришли к отрицанию общего духа их учения. Поэтому говоря о постпозитивистском видении научного знания, мы будем иметь в виду, прежде всего, эпистемологическую теорию К. Поппера («эпистемологию без познающего субъекта») и тех его последователей, которые в целом придерживаются ключевых положений его критического рационализма, не скачиваясь в сторону релятивизма (постмодернизма) (например, Х. Альберта). Считаем эту оговорку важной, поскольку в отече-

\footnotetext{
${ }^{1}$ Один из ведущих российских исследователей критического рационализма Поппера И.З. Шишков, например, утверждает, что «вся философия К. Поппера вращается вокруг кантовского трансцендентального вопроса, который он считал, наряду с проблемой индукции (юмовской проблемой), основной проблемой познания. K. Поппер именует эту проблему кантовской, обозначая ее как проблему демаркации». См.: Шишков И.З. Кант и критицистская традиция // Историко-философский ежегодник'99. - М. : Наука, 2001. - С. 168.

${ }^{2}$ Поппер K. Логика научного исследования. - М. : АСТ: Астрель, 2010. - С. 45.
} 
ственной философской традиции под постпозитивизмом обычно понимают философское направление, основанное Поппером и в том или ином отношении развитое Т. Куном, Ст. Тулмином, П. Фейерабендом, М. Полани и И. Лакатосом, хотя идеи указанных авторов во многом отошли от попперовского критического рационализма. Нечто подобное относится и к школе немецких идеалистов (И. Фихте, Ф. Шеллинг, Г. Гегель), которые, опираясь на некоторые философские идеи Канта, по сути, отвергли его эпистемологическую программу «коперниканского переворота» ${ }^{3}$.

Согласно Г. Сколимовскому, философию Поппера следует разделить на два периода: (1) методологический (с конца 1930-х до 1960х) и (2) метафизический (с 1960-х до 1990-х $)^{4}$. Причем в каждом из этих периодов Поппер разрабатывает различные аспекты проблемы научной объективности. Первый период связан с разработкой альтернативных вариантов решения основных методологических проблем, поставленных логическими позитивистами Венского кружка (проблемы демаркации научного знания, оснований, истины, источника познания, научного метода, соотношения эмпирического и теоретического уровней научного познания и др.). «Поппер расходился с логическими эмпириками не по тому или иному конкретному вопросу, а по поводу всей концепции науки и, следовательно, всей концепции человеческого знания» ${ }^{5}$. В ходе продуктивной дискуссии с логическими эмпириками Поппер оформил учение о научной объективности в смысле интерсубъективности (в контексте разработки критерия фальсификации и критической интерсубъективной проверки).

Начиная с 1960-х гг., согласно Сколимовскому, для Поппера начинается т. наз. метафизический период, в рамках которого он разрабатывает теорию «трех миров» и соответственно учение о научной объективности в смысле истинности. Причем Поппер принимает и далее разрабатывает семантическую теорию истины А. Тарского как соответствия знания фактам (в отличие от соответствия знания действительности в рамках классической аристотелевской теории истины). Можно даже сказать, что семантическая теория истины - это

\footnotetext{
${ }^{3}$ Более детально об этом см.: Панафидина О.П. Трансцендентализм И. Канта и немецкий идеализм (К вопросу о некоторых стереотипах экспликации кантовской теоретической философии) // Вопросы философии. - М., 2011. - № 4. - С. 177-186.

${ }^{4}$ Сколимовский Г. Карл Поппер и объективность научного знания // Эволюционная эпистемология и логика социальных наук: Карл Поппер и его критики. М. : Эдиториал УРСС, 2000.- С. 242-267.

${ }^{5}$ там же. - C. 245.
} 
преломленная через кантовскую эпистемологию теория соответствия Аристотеля. Если исследователь говорит о соответствии знания действительности, то он исходит из метафизической (в классическом понимании) установки и предлагает устанавливать связь между миром1 (миром физических явлений) и миром-2 (миром субъективных ментальных сущностей). Размежеванием ноуменов и феноменов Кант, как известно, подверг основательной критике классическую экспликацию метафизики как науки о первых основах сущего и их истинном познании. Согласно эпистемологической теории Канта, субъект познания имеет дело с феноменами, следовательно, только они могут выступать объектом научного познания. Для Поппера первостепенное значение во второй период приобретает не столько сам процесс познания, сколько его результат - определенным образом оформленное знание. Поэтому для него более важным является установление связи между миром-2 и миром-3 (т.е. миром объективного содержания мысли, миром научных теорий, проблем и т.д.). Человеческая мысль объективируется с помощью артикулированной речи (вторая сигнальная система), поэтому факт необходимо рассматривать в качестве простейшей формы организации нашего научного знания, выраженного в лингвистической форме (т.е. в качестве эпистемологического, а не онтологического понятия). В результате семантическая теория истины предполагает установление связи между субъективным процессом познания и объективным научным знанием.

Итак, мы утверждаем, что понимание научной объективности в смысле интерсубъективности и истинности, предложенное в рамках критического рационализма Поппера, может быть применено к рассмотрению проблемы объективности исторического (шире гуманитарного) знания. Иначе говоря, историческая объективность, как и научная объективность в целом, может быть достигнута лишь в определенном смысле (с учетом интерналистской перспективы, несовершенства познавательных способностей субъекта, используемых им концептуальных каркасов и интерсубъективного характера научной деятельности).

Что касается обоснования возможности исторической объективности как интерсубъективности, то продуктивной представляется нам попперовская идея различения двух смыслов понятия знания: «(1) знание или мышление в субъективном смысле, состоящее из состояний ума, сознания или диспозиций действовать определенным образом; (2) знание или мышление в объективном смысле, состоящее из 
проблем, теорий и рассуждений, аргументов как таковых» 6 . Знание в субъективном и объективном смысле он связывает со своими вторым и третьим миром соответственно. Согласно Попперу, «традиционная эпистемология, то есть эпистемология Локка, Беркли, Юма и даже Рассела» «с ее концентрацией внимания на втором мире, или знании в субъективном смысле, не имеет отношения к исследованию научного знания», т.к. «для эпистемологии решающее значение имеет исследование третьего мира, являющегося в значительной степени автономным» ${ }^{7}$. Третий мир «объективного содержания мышления» порожден «дискуссиями» или «критическими спорами». Следовательно, научная объективность не может стать результатом стремления отдельно взятого ученого «быть объективным», ведь в таком случае речь идет о «субъективной уверенности» в истинности высказываний об изучаемых объектах. Об объективности можно говорить только тогда, когда исследователь допускает возможность конструктивной критики со стороны оппонентов. Любой ученый, стремящийся к получению научного знания, должен заниматься поиском «наилучших способов критики наших теорий (гипотез, догадок), а не защитой их против сомнений» ${ }^{8}$. Отсутствие же рациональной дискуссии между оппонентами означает, что они не находятся в сфере науки как таковой.

Итак, историческую объективность в смысле интерсубъективности следует признать возможной при условии возможности научной дискуссии между историками. Многие исследователи (К. Лоренц, А. Мегилл и др.) полагают, что в силу специфических особенностей истории как формы знания и ее особой роли в обществе споры между историками напоминают скорее нескончаемые политические дебаты, нежели научные дискуссии ${ }^{9}$. Речь идет, во-первых, о «практическом интересе истории», который способствует формированию индивидуальной и коллективной идентичности, и во-вторых, о «горизонте

\footnotetext{
${ }^{6}$ Поппер K.P. Объективное знание. Эволюционный подход. - М. : Эдиториал YPCC, 2002. - C. 111.

${ }^{7}$ Там же. - C. $110,113$.

${ }^{8}$ Поппер К. Логика научного исследования. - М. : АСТ: Астрель, 2010. - С. 111, примеч. ${ }^{*} 1$.

${ }^{9}$ Современный нидерландский исследователь К. Лоренц прекрасно проиллюстрировал данный тезис на примере известного спора немецких историков по поводу нацистского прошлого (Historikerstreit). См.: Lorenz C. Historical Knowledge and Historical Reality: A Plea for «Internal Realism» // History and Theory: Contemporary Readings. - London : Oxford, 1998. - Р. 342-376. Русскоязычный перевод данной статьи см.: Лорени $K$. Историческое знание и историческая действительность: в защиту «внутреннего реализма» // Личность. Культура. Общество. - М., 2012. - Т. 14. Вып. 1. - С. 70-81; Вып. 2. - С. 89-98; Т. 14. Вып. 3. - С. 71-89.
} 
ожидания» со стороны заинтересованной аудитории, к которой обращены исторические тексты. В результате, как утверждает Лоренц, «история может быть истинной, но неприемлемой» ${ }^{10}$. Более того, в историческом исследовании очень тесно взаимосвязаны факты и ценности ${ }^{11}$, поэтому даже когда историки апеллируют к «действительности», «истине» и «фактам» это вовсе не гарантирует достижения объективного знания. Ведь другой историк, апеллируя к той же «действительности», может прийти к совершенно иным выводам касательно того, что считать «историческим фактом». Причина данного явления коренится в том, что Лоренц называет «нормативным выбором историка», т.е. в наличии некоего «концептуального каркаса», определенной «перспективы видения» или «точки зрения».

Следует ли из этого, что рациональные научные дискуссии между историками в принципе невозможны? С нашей точки зрения, такие дискуссии возможны в рамках профессиональной историографии (в отличие от непрофессиональной, к которой А. Мегилл относит социальную память, эстетические репрезентации и популярную историографию ${ }^{12}$, но при условии соблюдения следующих требований, вытекающих из основных интенций критического рационализма Поппера:

(1) свою теорию необходимо рассматривать не в качестве некой «тотальной идеологии», претендующей на безусловную истинность, а - этапа в приближении к истине;

(2) должно исходить из установки, что исторические тексты презентуют определенный взгляд на исторические события, поэтому являются скорее гипотезами, нежели завершенными теориями;

(3) нужно быть готовым не только критиковать точку зрения своего оппонента, но и пересматривать отдельные положения своей теории, или даже отбрасывать ее в целом;

(4) наконец, целью дискуссии должна провозглашаться не победа любой ценой, а хоть малейшее приближение к истине.

${ }^{10}$ Lorenz C. Historical Knowledge and Historical Reality... - P. 357, 364.

${ }^{11}$ См.: Панафідіна О.П., Мішалова О.В. Факти і цінності в історичному дослідженні: дихотомія чи взаємозв'язок? // Актуальні проблеми духовності: [зб. наук. праць]. - Кривий Ріг : ДВНЗ «КНУ», 2012. - Вип. 13. - С. 25-42.

${ }^{12}$ Мегилл A. Некоторые соображения о проблеме истинностной оценки репрезентации прошлого // Эпистемология и философия науки. - M., 2008. - T. XV, № 1. C. 53 . 
Итак, историческая объективность как интерсубъективность в принципе возможна, если историк исходит из научных мотивов своей деятельности и рассматривает научное познание как непрекращающийся процесс поиска истины в рамках научного сообщества (и наоборот, она невозможна, если историк позиционирует себя в качестве публициста, писателя, общественного деятеля или «слуги политики», поскольку в таком случае рациональные аргументы оппонентов на него не действуют). В связи с этим необходимо обратиться ко второму аспекту попперовского понимания научной объективности в смысле истинности и обосновать возможность аналогичной объективности исторического знания.

Что касается экспликации исторической объективности как истинности, то обоснование ее возможности связано с пониманием истины в русле семантической теории А. Тарского. Поппер считает, что данная теория «спасает» теорию корреспонденции, критикуемую представителями т. наз. «субъективистских теорий истины» (прагматистской, когерентной и теории очевидности). Достаточно продуктивным представляется нам предложенное Поппером разграничение между истиной и правдоподобностью, или «близостью к истине». Если абсолютная и объективная истина является регулятивным принципом (в кантовском смысле) познавательной деятельности ученого, то правдоподобность - характеристика знания, полученного путем критических дискуссий на том или ином этапе научного познания. Т.е., поскольку ни один человек не может претендовать на достижение абсолютной истины, как и сообщество таких людей в целом, то истина - это своеобразный познавательный ориентир для ученых. Следовательно, процесс научного познания представляет собой перманентный поиск истины. В связи с этим Поппер говорит о важности «интеллектуальной скромности», «осознания ограниченности [познавательных] возможностей отдельного человека», «взаимной критики», владения «искусством прислушиваться к критике», «принимать во внимание прежде всего доказательства, а не личность доказывающего» ${ }^{13}$.

Известно, что универсальным методом научного познания Поппер считает метод проб и ошибок, обеспечивающий постепенное приближение к истине. Условиями успешного применения этого метода можно считать следующие: «предлагаемые теории должны быть достаточно многочисленны (и оригинальны); они должны быть достаточно раз-

${ }^{13}$ Поппер K.P. Открытое общество и его враги. Т. 1: Чары Платона; Т. 2: Время лжепророков: Гегель, Маркс и другие оракулы. - К. : Ника-Центр, 2005. - С. 404406. 
нообразны; осуществляемые проверки должны быть достаточно строги» ${ }^{14}$. Коллективное использование учеными метода проб и ошибок способствует развитию научного знания, т.к. позволяет увидеть свои ошибки вследствие критики со стороны. Причем в данном контексте деятельность историка может быть представлена в более выгодном положении, нежели это было ранее. Речь идет о пресловутой проблеме «переписывания истории». Традиционно факт «переписывания истории» рассматривался как один из аргументов в пользу тезиса о ненаучности истории. Однако в рамках постпозитивистской экспликации научного знания этот процесс приобретает научную легитимность.

Историки исследуют не тот или иной аспект сущего, но «остатки» прошлого с целью восстановить картину ушедшей в небытие действительности. Отсутствие «реального» объекта познания на современном этапе развития научного знания перестало относиться исключительно к истории. Например, астрономы изучают не только обозримую часть Вселенной, но и «необозримую». Состояние современной науки во многом напоминает состояние античной науки как некой «второй философии» в аристотелевском понимании, т.е. она развивается прежде всего как теоретическая наука, в которой объект исследования выступает как идеализированный, мысленно конструируемый. Следовательно, деятельность ученого начинается, как говорил Поппер, с формулирования проблемы и выдвижения рабочих гипотез, и только затем он обращается к эмпирической действительности, причем не для того, чтобы доказать истинность какой-либо гипотезы, а чтобы попытаться ее опровергнуть.

В естественных науках, которые традиционно рассматривались гуманитариями в качестве эталона научности, постоянно происходит нечто напоминающее «переписывание истории». Это связано со стремлением уточнять полученное научное знание и, конечно же, с его развитием. Как отмечает А.Л. Никифоров, процесс смены научных теорий можно сравнить с картинами мира, создаваемыми ребенком и взрослым. «Взрослый человек воспринимает мир в значительной мере не так, как ребенок: его картина мира значительно полнее, глубже, в ней отсутствуют какие-то объекты, входящие в картину мира ребенка; однако взрослый человек вполне способен понять, почему ребенок рисует себе мир так, а не иначе». Каждая новая теория вводит новую онтологию и «либо расширяет аспект рассмотрения, углубляет его,

${ }^{14}$ Поппер K.P. Предположения и опровержения: Рост научного знания. - М. : ACT, 2008. - C. 517. 
либо изменяет. Поэтому новая теория способна объяснить и показать, почему истинные утверждения старой теории были и остаются истинными» ${ }^{15}$.

Попперовская идея роста научного знания также может быть применена для анализа процесса «переписывания истории», хотя и с учетом определенной специфики исторической науки. Историческое знание (в рамках профессиональной историографии) необходимо должно уточняться и обновляться по следующим причинам:

(1) все следствия исторических событий неизвестны ни одному участнику этих событий и ни одному историку, т.к. некоторые следствия могут проявиться в отдаленном будущем. Поэтому в свете вновь открывшихся следствий может быть предложен новый способ описания давно произошедших событий;

(2) согласно Е.X. Карру, «факты прошлого» и «исторические факты» не являются тождественными понятиями ${ }^{16}$. Первые стают вторыми, когда к ним обращается историк, когда он формулирует проблемы и актуализирует тот или иной корпус исторических источников;

(3) поскольку исторический дискурс имеет фактуально-нормативный характер ${ }^{17}$ т.е. в нем переплетены описательный и концептуально-теоретический уровень исследования, то следует признать, что новые факты могут способствовать трансформации «точки зрения» («перспективы») историка, и наоборот, новая «точка зрения» может повлиять на формирование оригинальной исторической концепции, по-новому интерпретирующей известные факты;

(4) научная дискуссия между историками в рамках профессиональной историографии, о принципиальной возможности которой мы говорили выше, также может стимулировать процесс «переписывания истории», т.к. ее целью должен быть поиск исторической истины.

Л.А. Микешина считает, что использование классического понимания истины, предложенного еще Платоном, сегодня является доста-

${ }^{15}$ Никифоров А.Л. Понятие истины в теории познания // Эпистемология и философия науки. - M., 2008. - T. XVI, № 2. - C. 64 .

${ }^{16}$ Carr E.H. What is history? - London: Penguin Books, 1987. - P. 10-13.

${ }^{17}$ Lorenz C. Historical Knowledge and Historical Reality... - P. 350. 
точно проблематичным, однако в то же время она предлагает различать релятивность знания и релятивизм. Под релятивностью Микешина понимает «свойство самого знания, отражающее изменчивость объекта, обстоятельств его существования и способов его интерпретации», а под релятивизмом - «тенденцию абсолютизации релятивности знания» ${ }^{18}$, которая логически приводит к отрицанию объективной истины. Признание релятивности знания не должно вести к релятивизму; иначе человеческий разум, как указывали Р. Декарт, И. Кант, K. Поппер и многие другие, просто запутается в противоречиях, поскольку способен доказать что угодно. «Отказ от понятия истины, хотя и не лишает нас способности рассуждать, однако уничтожает разницу между рассуждением и шизофреническим бредом» ${ }^{19}$. Интересно, что в психиатрических исследованиях установлена связь между шизофреническим мышлением и отрицанием основных законов аристотелевской логики (закона тождества, закона исключенного третьего и закона (не)противоречия). Как отмечает В.И. Менжулин, «весьма символично, что из четырех законов формальной логики, лишь первые три, т.е. те, которые были сформулированы самим Аристотелем, категорически игнорируются шизофреническим мышлением. Четвертый закон (достаточного основания), введенный двумя тысячелетиями позднее (Лейбницем), шизофреническим мышлением не отбрасывается, а лишь частично модифицируется» ${ }^{20}$.

Следует отметить, что с законом достаточного основания связано оформление такого эпистемологического направления, как джастификационизм. Согласно Х. Альберту, «классическая методология. . . была ориентирована, в сущности на методологическую версию закона достаточного основания, а именно на идею, что любая точка зрения, любое убеждение, любая мысль должна оправдываться ссылкой на позитивные, надежные основания, незыблемый фундамент» ${ }^{21}$. Ища некую архимедову опорную точку, классический рационалист исходил из совместимости поиска истины и стремления к достоверности, тем самым приходил к признанию существования непогрешимых истин, следовательно, к потенциальному догматизму. «Новая концепция рацио-

\footnotetext{
${ }^{18}$ Микешина Л.А. Философия познания. Проблемы эпистемологии гуманитарного знания. - М. : Канон +, 2009. - С. 396.

${ }^{19}$ Никифоров А.Л. Понятие истины в теории познания... - С. 54.

${ }^{20}$ Менжулин В.И. Философия с «меркантильной» точки зрения // Актуальні проблеми духовності. - Зб. наук. праць. - Кривий Ріг : I.B.I., 2002. - Вип. 4 (1). C. 194.

${ }^{21}$ Aлъберт X. Трактат о критическом разуме. - М. : Эдиториал УРСС, 2010.C. 56 .
} 
нальности, воплощенная в принципе критической проверки», т.е. основанная на критическом рационализме Поппера, по сути, предлагает модифицировать процедуру обоснования научного знания. Последнее приобретает интерсубъективный характер. Как следствие, «объективность отделяется от абсолютности, несомненности, от "твердых" фактов и "непредубежденного" наблюдения, которые обычно сплетаются в общий узор в традиционных концепциях объективного знания» 22 .

В результате вышеизложенного напрашивается вывод, что понятие истины в принципе должно быть сохранено в качестве характеристики того знания, на получение которого претендуют ученые. Хотя согласно идее роста научного знания единственным критерием истинности может быть признано лишь постепенное и постоянное приближение к истине, но не овладение ею. В контексте критики релятивизма на необходимость сохранения понятия истины как условия любого суждения вообе в гуманитарных науках, в частности в истории, указывал и неокантианец Г. Риккерт. Ведь если признать, что «существует только относительная истина, следовательно, значит, нет никакой разницы между глупым суеверием и научным исследованием. . . Слово "истина" вообще совершенно теряет свой смысл, который у него есть только тогда, когда одна истина выставляется в противоположность многим индивидуальным мнениям» ${ }^{23}$. Итак, без признания существования объективной исторической истины «испаряются» границы между фактом и вымыслом, между историей и литературой.

Следует также обратить внимание на тот факт, что Поппер, в целом признавая лингвистический поворот в философии, предлагает исследовать проблему объективности знания через призму языка. Согласно Попперу, язык является «необходимым средством критического обсуждения, дискуссии». «Хотя третий мир не идентичен миру лингвистических форм, он возникает вместе с аргументативной функцией языка, являясь его побочным продуктом» 24 . Знание-все то, что может быть выражено в знаково-символической форме, следовательно, дешифровано любым субъектом познания. Поэтому необходимым условием объективного знания является «то, что оно должно быть выражено посредством межсубъектных символов» ${ }^{25}$, а таковыми есть

${ }^{22}$ Сколимовский Г. Карл Поппер и объективность научного знания ...- С. 248.

${ }^{23}$ Риккерт Г. Введение в трансцендентальную философию // Риккерт Г. Философия жизни. - К. : Ника-Центр, 1998. - С. 99.

${ }^{24}$ Поппер K.P. Объективное знание. Эволюционный подход. - М.: Эдиториал УPCC, 2002. - C. 137.

${ }^{25}$ Сколимовский Г. Карл Поппер и объективность научного знания ... - С. 263. 
прежде всего знаки природного языка. Именно поэтому язык для Поппера важен не столько как средство самовыражения, сколько как инструмент рациональной коммуникации. Этот аспект критического рационализма наглядно демонстрирует взаимосвязь между миром-2 и миром-3 при одновременном сохранении автономности последнего. Можно также сказать, что знание как истинное обоснованное мнение получено эмпирическим субъектом и является достоянием мира- 2 , но в результате критической дискуссии, с помощью оперирования «межсубъектными символами», вырабатывается такое знание, которое является достоянием социального субъекта и относится к миру-3.

Таким образом, признавая тот факт, что понятие «гуманитарное знание» не является тождественным понятию «гуманитарное научное знание», мы полагаем, что определенная часть знания о человеке и о культуре все же должна соответствовать общим критериям научности. По крайней мере, на это претендуют, например, практикующие историки, использующие такие эпистемологические категории, как «факт», «знание», «объективность», «истина» и др. Однако ориентация историков на идеалы классического естествознания порождает множество методологических проблем, без разрешения которых невозможно обоснование научного статуса истории. Одной из таких проблем является проблема объективности исторического знания. В данной статье мы попытались доказать, что даже с учетом предметной специфики исторической науки к ней в целом применима методология критического рационализма Поппера, во многом продолжающая традиции кантовской эпистемологии. Главный наш вывод состоит в том, что объективное историческое знание, как и объективное научное знание в целом, возможно в смысле интерсубъективности и истинности.

Надійшла до редакиї 27 червня 2015 р. 